\title{
TURISMO EM PARQUES NACIONAIS BRASILEIROS: CONHECER PARA CONSERVAR
}

\author{
Joana da Silva Castro Santos ${ }^{1}$ \\ Maria Constança Madureira Homem de Carvalho
}

\section{RESUMO}

O Brasil está entre os países detentores dos mais expressivos números de áreas naturais protegidas. O turismo, sendo uma forma de lazer, se populariza cada vez mais pela necessidade de eliminar o estresse advindo do processo de urbanização e industrialização das cidades. Desse fato decorre um dos motivos para o número crescente de viajantes em busca de lugares exóticos, de beleza cênica e recursos naturais. As Unidades de Conservação (UC) são áreas voltadas para a proteção da natureza e uso responsável de seus recursos, buscando causar o menor impacto possível, em especial, naqueles onde há visitação, como nos parques nacionais. A criação de UCs envolve mais do que questões ecológicas, pois contribui também para a geração de emprego e renda, e garante a satisfação da população e dos visitantes. Este trabalho pretende explicitar o papel do turismo em parques nacionais em prol do desenvolvimento socioeconômico e da conservação ambiental.

Palavras Chave: Turismo; Unidades de Conservação; Parques Nacionais

\begin{abstract}
Brazil is among the countries that hold the largest numbers of protected areas. Tourism, being a form of leisure, becomes popular more and more due to the need to cope with the stress arising from the process of urbanization and industrialization of the cities. This explains the reason why the number of travelers has grown significantly in search of exotic places, scenic beauty and natural resources. Conservancies (or Conservation Units, in Brazil) are areas aimed at the protection of nature and responsible use of its resources, with minimum impact, especially in areas where visitation is allowed, as in national parks. The creation of protected areas involves more than ecological issues, it also contributes to the increase of job opportunities and to generate income, besides guaranteeing satisfaction of the native population and visitors alike. The purpose of this essay is to analyze the role of tourism in national parks and its contribution to socio-economic development and environmental conservation.
\end{abstract}

Keywords: Tourism; Conservation Units; National Parks

\footnotetext{
${ }^{1}$ Licenciada em Turismo pela Universidade Federal Rural do Rio de Janeiro. E-mail: joanascsantos@gmail.com

${ }^{2}$ Advogada formada pela Universidade Candido Mendes (UCAM), Rio de Janeiro, professora no Curso de Direito da UCAM, coordenadora e professora no Curso de Turismo na UCAM, Rio de Janeiro, mestre em Direito Econômico e Desenvolvimento pela UCAM, Rio de Janeiro, RJ. E-mail: $\underline{\text { mcmhc@ @lobo.com }}$
} 


\section{INTRODUÇÃO}

Ao mesmo tempo em que o Brasil ostenta um dos maiores índices de biodiversidade do planeta, representando $20 \%$ de tudo que há de vida na Terra, e é considerado a nação número um no mundo em beleza cênica e recursos naturais. Entretanto, não figura sequer entre os 50 primeiros, quando o quesito é competitividade em turismo (RIVA, PETTA, 2014). Além disso, o País ostenta um dos maiores percentuais de espaços protegidos, entre eles, os parques nacionais, que correspondem a cerca de $15 \%$ do território nacional (SEMEIA, 2015).

Há vários tipos de turismo que servem a diferentes perfis de turistas. Entre todos, o turismo de natureza é um dos que mais têm crescido. E, numa linha de coerência, esse segmento turístico nos remete à compatibilização inevitável de sua prática em Unidades de Conservação (UC), sobretudo em parques nacionais.

Incentivar a visitação nos parques nacionais pressupõe o estímulo e a consolidação de uma cultura de responsabilidade de conservação às áreas protegidas, a começar dentro do próprio País. Ato contínuo, só se conserva o que se conhece. A propagação da atividade turística no ambiente dos parques nacionais nos parece uma opção factível por englobar a participação democrática de todos os envolvidos na matéria (setores público e privado, sociedade civil, por exemplo) na justa medida dos seus papeis e interesses.

O turismo permite, diante de boas práticas, geração de renda, emprego e divisas, oferta de diversões, conhecimento e acesso à cidadania sem distinção de público. Também indissociável ao turismo está o desenvolvimento sustentável, elo sadio que deverá existir entre a atividade humana e a conservação do meio ambiente. A nosso ver, enfatizar o bom e adequado planejamento e gestão de turismo em parques nacionais responde pelo sucesso dessa premissa. Vejamos a seguir.

\section{ANÁLISE SOCIOECONÔMICA E AMBIENTAL}

Cabe ao Estado concentrar forças e recursos na implantação de infraestrutura básica em destinos turísticos, a começar por aqueles localizados em áreas de conservação ambiental. Perda de receita, desestímulo ao empreendedorismo, falta de cultura e orgulho da população pelos atrativos naturais do país, entraves ligados às fontes de custeio, ao licenciamento ambiental, ao relacionamento precário com as comunidades locais, estão entre os gargalos enfrentados quando se trata de fomentar o desenvolvimento socioeconômico e sustentável pela via do turismo nesses ambientes.

As UCs, especialmente aquelas onde o uso público pela visitação é permitido, têm se revelado um instrumento exitoso na conciliação e alcance de metas ligadas a conservação e desenvolvimento socioeconômico e sustentável.

No modelo atual do Estado brasileiro, a partir de ditames constitucionais, cabe a ele a função de planejamento e regulação, afastando sua participação direta na atividade econômica. Por outro lado, a presença dos agentes privados na exploração da atividade turística nas áreas protegidas ambientalmente permite que o governo se dedique às suas funções diretivas, fomentadores, essenciais. E, com a expertise que lhe é própria, o setor 
privado pode empreender, dentro dos limites da livre iniciativa, do acesso ao mercado e do empreendedorismo.

Essa interação se configura, pois, num processo de ganha-ganha. De um lado, é possível dinamizar a economia de regiões naturais e/ou remotas, como é o caso daquelas situadas no interior dos parques nacionais. De outro, se alia à conservação ambiental porque, diante da possibilidade de visitar e conhecer, as próprias populações tradicionais e, por consequência, os visitantes passam a apreciar e cultuar os atrativos naturais, preservando-os não só para o deleite como pela sua integridade. Em paralelo, o incremento da visitação aos parques nacionais, que atualmente sofrem de uma falta crônica de recursos, pode reverter em solução para problemas como falta de funcionários, ausência de planos de manejo, fiscalização deficiente, entre outros. A exploração econômica sustentável dos parques é um tipo de investimento pouco visível pelo seu vulto e pelo retorno de longo prazo. Neste quesito, a participação privada deve ser considerada uma alternativa importante de investimento. A experiência internacional deve ser fonte de inspiração (e não de cópia) para o Brasil.

\section{TURISMO E GLOBALIZAÇÃO}

O lazer (e o turismo é uma das suas formas), como necessidade numa sociedade que precisa estar em equilíbrio e gerar novas fontes econômicas, ganha um ritmo acelerado. $\mathrm{O}$ turismo exige novos modelos de espaços correspondentes aos novos tipos de relações no nível humano, além de contribuir para a circulação de capital, melhoria econômica de uma região e o consumo dos lugares e do meio ambiente. A atividade turística surge como resposta a uma necessidade de descompressão, resultante da própria dinâmica do sistema da sociedade industrial. A carência por uma atividade turística aumenta nas sociedades pós-industriais ou pós-modernas, e a ampliação do tempo livre das pessoas é uma das causas da demanda crescente pelo turismo (SANTOS, 2002).

A globalização se potencializa com o turismo, uma vez que, com a maior abertura das fronteiras, as pessoas viajam mais livremente, têm oportunidade de relacionar-se mais e melhor, sobretudo quando se consegue fazer um turismo com grande consciência ambiental, com pessoas interessadas em conhecer outras realidades, conviver com outras culturas, reconhecer a alteridade. Os lugares preferidos são os exóticos e os histórico/culturais, intermediados por agentes da produção do espaço turístico, tais como: "apropriadores" do território (proprietários, grileiros, posseiros (...) ou incorporadores); Estado; produtores de novas edificações para "pouso" dos turistas, indústrias de construções, de imobiliárias, de equipamentos de bens de consumo duráveis e os próprios turistas (RODRIGUES, 1996: 58-59 apud FONTELES, 1999). Todos estes agentes se beneficiam com a globalização, interligando-se nas modernas técnicas de comunicação que globalizam o som, as imagens, as cores dos lugares potencialmente turísticos, vendendo-os de forma que as suas paisagens se tornam familiares e interessantes (FONTELES, 1999).

Sustentabilidade é palavra de ordem que pressupõe o uso sensato, apropriado e eficiente dos recursos naturais, de maneira ambientalmente responsável, socialmente justa e economicamente viável, de forma que o atendimento das necessidades atuais não comprometa 
a possibilidade de uso pelas futuras gerações. Inerente às discussões contemporâneas, a vinculação do binômio atividade humana versus preservação do meio ambiente não exclui o turismo sustentável. O desenvolvimento tradicional de um destino turístico pode levar ao esgotamento dos recursos naturais, à descaracterização do patrimônio cultural e à desestruturação da rede social. Quando um destino começa a perder seus encantos por essas razões, corre-se o risco de ser preterido pelos turistas em busca de outro "paraíso". Diante disso, o novo paradigma do turismo sustentável abrange fatores como a autenticidade cultural, a inclusão social, a conservação do meio ambiente e a qualidade dos serviços como peças fundamentais para sua viabilidade econômica no longo prazo (CARVALHO, 2014).

O crescente interesse em torno do estudo do turismo como atividade econômica devese ao fato de que, como tal, tem sido pouco estudado entre nós. Trata-se de interesse legítimo, levando-se em conta que as análises estão voltadas para subsidiar ações para o bom manejo dos recursos naturais e culturais ligados ao turismo, consideradas as dimensões continentais e diversidades naturais, culturais, artísticas, artesanais, históricas. A elaboração de políticas públicas de turismo deve atuar nos dois sentidos: ao promover a atividade econômica, reverte em prol da erradicação da pobreza, da desigualdade social e contribui para o desenvolvimento sustentável (CARVALHO, 2014).

\section{UNIDADES DE CONSERVAÇÃO: CATEGORIAS, OBJETIVOS E USOS}

Em um planeta com aproximadamente 7 bilhões de habitantes, que consome vorazmente seus recursos naturais, a maior parte deles não-renováveis, as áreas de conservação mundiais tornam-se um assunto cada vez mais importante.

As áreas naturais protegidas ou Unidades de Conservação (UC), como são designadas no Brasil, são espaços legalmente instituídos com o objetivo de proteger a natureza, seja do ponto de vista da preservação da biodiversidade e das belezas paisagísticas ou da utilização sustentada dos ecossistemas e seus recursos naturais. Do ponto de vista geográfico, podemos entender as UCs como uma forma de institucionalização do espaço e uma expressão de seu controle político (RÖPER, 1999 apud CAVALCANTE, FURTADO, 2011).

Para Lima (2003), as UCs vêm se constituindo como uma das principais estratégias para a conservação da natureza. Entre os séculos XVI e XIX, a qualidade do ambiente passou a ser elemento de destaque do produto turístico, de modo que a natureza e seus componentes tornaram-se pretextos para a descoberta, a educação e o espírito de aventura, dando origem a um novo mercado (CAVALCANTE, FURTADO, 2011). Esse mercado refere-se ao turismo na natureza, que ocupa espaço na expressão "turismo alternativo" e que, segundo Pires (2002, p. 111) "pode ser entendida como uma expressão (...) impregnada de anseios e ideais de mudanças e inovação do turismo convencional de massas (...), e como chave designativa de um turismo diferenciado em relação ao convencional ou tradicional (...)". A partir disso, temse uma variedade de tipos alternativos de turismo, como o ecoturismo (BUENO, PIRES, 2006) e o turismo de aventura, cujas características envolvem, respectivamente, o turismo interpretativo, de baixo impacto, voltado à busca de conservação e entendimento do meio ambiente (FARIAS, CASTILHO, 2006) e a prática esportiva em ambientes naturais (ciclismo, arvorismo, trekking, por exemplo). Portanto, a partir da identificação com os segmentos do 
turismo na natureza, áreas remotas e partes dos territórios relativamente pouco alterados dos países estão se convertendo em destinos favoritos para turistas nada convencionais (CAVALCANTE, FURTADO, 2011).

Atualmente as UCs brasileiras são regulamentadas pelo Sistema Nacional de Unidades de Conservação (SNUC), instituído pela Lei $\mathrm{n}^{\circ}$ 9. 985, de 18 de julho de 2000, e regulamentada pelo Decreto $\mathrm{n}^{\circ}$. 4.340, de 22 de agosto de agosto de 2002 (BRASIL, 2000).

O SNUC as divide em dois grupos, compostos por categorias. As Unidades de Conservação de Proteção Integral compreendem a (o): (i) Estação Ecológica, (ii) Reserva Biológica, (iii) Parque Nacional, (iv) Monumento Natural, (v) Refúgio de Vida Silvestre. Entre as Unidades de Conservação de Uso Sustentável figuram a (o): (i) Área de Proteção Ambiental, (ii) Área de Relevante Interesse Ecológico, (iii) Floresta Nacional, (iv) Reserva Extrativista, (v) Reserva de Fauna, (vi) Reserva de Desenvolvimento Sustentável, (vii) Reserva Particular do Patrimônio Natural (ICMBIO).

É notável que a beleza cênica, juntamente com os elementos histórico-culturais existentes nas áreas naturais, sobretudo as protegidas legalmente, represente polos de atração e recepção de turistas e visitantes. Apesar de as UCs serem locais destinados à conservação ambiental, exercício da educação ambiental, pesquisa científica e contemplação da natureza em seu estado original ou mais próximo deste, a prática da atividade turística muitas vezes não atende esses princípios. Assim, ela é muitas vezes vista apenas como positiva à natureza. Contudo, o turismo também provoca impactos negativos, degradantes e agressores ao meio ambiente (RUSCHMANN, 2005 apud CAVALCANTE, FURTADO, 2011).

Diante dos problemas oriundos do desenvolvimento do turismo em áreas naturais, destaca-se a necessidade de se estabelecer parâmetros para seu crescimento, com o intuito de monitorar e planejar tais atividades, apontando propostas para minimizar os impactos nos dois sentidos, tanto em favor do meio ambiente, como das populações nativas (CAVALCANTE, FURTADO, 2011).

A Organização Mundial do Turismo (OMT, 2003) entende que o turismo sustentável, e seguro, deve atentar para todos os aspectos da diversidade cultural e institucional, privilegiando aspectos físicos e ambientais capazes de influenciar diretamente nas condições de saúde, qualidade de vida e segurança das pessoas e comunidades. A necessidade de se trazer a dimensão ambiental para a dinâmica do desenvolvimento da atividade turística nasceu nesse cenário. De acordo com a International Union for Conservation of Nature (IUCN), a criação de Unidades de Conservação é medida que melhor exemplifica a tentativa de preservar os recursos naturais e a vida dos diversos ecossistemas em áreas protegidas, e seus princípios devem ir além das questões ecológicas, já que compreendem também a melhoria das condições econômicas e sociais das populações locais, além da satisfação dos visitantes do destino (WANDERLEY-FILHA, AZEVEDO, NÓBREGA, ALBUQUERQUE, 2013). 
Políticas públicas ${ }^{3}$ de turismo devem considerar que, sendo os elementos do espaço (meio físico, social e cultural) a "matéria-prima" da atividade turística, sua inter-relação com o meio ambiente é incontestável. Em alguns estados, como Amazonas e Pará, por exemplo, essas populações começaram a se organizar em associações para reivindicar às autoridades do Instituto Brasileiro de Meio Ambiente e Recursos Naturais e Renováveis (IBAMA) seus direitos ao território ancestral e à manutenção de seus hábitos e costumes tradicionais (MORAES, 2006). Assim, essas áreas podem contribuir para a manutenção de exemplos dinâmicos de relação harmoniosa entre homem e natureza para as sociedades urbanoindustriais, porém conhecemos pouco sobre esses sistemas; e a chave para o entendimento das atividades sustentáveis em ambientes frágeis começa com as populações tradicionais (DIEGUES, 2004 apud MORAES, 2006).

\section{TURISMO EM PARQUES NACIONAIS BRASILEIIROS: CONHECER PARA CONSERVAR}

A gestão do turismo em UCs precisa propor o ordenamento das atividades humanas nesses espaços para que estas originem o menor impacto possível sobre o meio. O artigo 225 da Constituição Federal, ao mesmo tempo em que estabelece "o meio ambiente ecologicamente equilibrado" como direito e como "bem de uso comum do povo e essencial à sadia qualidade de vida", também impõe ao "Poder Público e à coletividade o dever de defendê-lo e preservá-lo para as presentes e futuras gerações” (WANDERLEY-FILHA, AZEVEDO, NÓBREGA, ALBUQUERQUE, 2013).

Com isso em mente, incumbe, pois, ao Poder Público o estímulo e regulação do desenvolvimento do turismo de modo a beneficiar a comunidade local sob a forma de infraestrutura básica e de implementação de leis em prol da melhoria da saúde pública, da segurança, do meio ambiente, do oferecimento de facilidades públicas (estacionamentos, praças e jardins, por exemplo), da promoção da imagem e marketing do destino, do estímulo à hospitalidade da comunidade (criação de Centro de Visitantes, por exemplo). Ainda, a atuação governamental deve se pautar em estratégias claras para a implementação de uma política de turismo local e regional, tudo isso com vistas às metas a serem alcançadas e com base em planejamento participativo. À iniciativa privada, com a expertise que lhe é própria, cabe desenvolver e executar as atividades de exploração e preservação das atrações turísticas. Nos parques nacionais, onde prevalece o sistema de concessões, maior é o volume de recursos aportados.

Há inúmeras ilustrações ao redor do mundo de como os parques nacionais são dinamizadores das economias nos territórios em que se encontram inseridos. O Banff National Park, no Canadá, em 1888, na época da abolição da escravatura no Brasil, já firmava contrato de concessão com o setor privado. Hoje, na África do Sul, 75\% das despesas dos

\footnotetext{
${ }^{3}$ Políticas públicas são conjuntos de programas, ações e atividades desenvolvidas pelo Estado diretamente ou indiretamente, com a participação de entes públicos ou privados, que visam assegurar determinado direito de cidadania, de forma difusa ou para determinado seguimento social, cultural, étnico ou econômico. As políticas públicas correspondem a direitos assegurados constitucionalmente ou que se afirmam graças ao reconhecimento por parte da sociedade e/ou pelos poderes públicos enquanto novos direitos das pessoas, comunidades, coisas ou outros bens materiais ou imateriais.
} 
parques nacionais são custeados pelos ingressos. No Parque Nacional de Fiordland, na Nova Zelândia - onde o turismo, em boa parte associado às áreas protegidas e comunidades tradicionais, representa cerca de $10 \%$ do PIB, a parceria gera mais de $50 \%$ dos empregos no sul do país (SEMEIA, 2012). Outras referências internacionais incluem: (i) Parque Nacional do Manu (Andes Peruanos); (ii) Parque Nacional Torres del Paine (Chile); (iii) Parque Nacional Vulcão Arenal (Costa Rica); (iv) Parque Nacional Nahuel Hapi (Argentina); (v) Agulhas National Park (África do Sul), para mencionar algumas.

Segundo pesquisa realizada pelo Instituto Semeia, em 2012, de um total de 100 parques brasileiros, $80 \%$ sequer gerava receita para visitação, e $21 \%$ não recebiam qualquer tipo de turista. Dos que recebiam visitantes, $58 \%$ apresentavam bilheteria inferior a 50 mil visitantes por ano. Se, por um lado, protegemos $18 \%$ do território nacional, contabilizando 1,5 milhão de $\mathrm{km}^{2}$, sob a forma de áreas protegidas (área correspondente ao território da Alemanha), por outro, menos de 6 milhões de pessoas (por ano) visitam os parques brasileiros, contra 280 milhões de visitantes nos similares norte-americanos. Apesar de o Brasil haver expandido sua área total protegida em 83,5\% entre 2001 e 2010, não houve o necessário incremento nos investimentos públicos (RIVA, PETTA, 2014).

Há, contudo, nesse contexto pouco animador, duas iniciativas dignas de menção por terem gerado resultados positivos, frutos de parcerias público-privadas para gestão e conservação, e de investimentos básicos em infraestrutura. Ambas em Minas Gerais são elas: a Rota das Grutas Peter Lund e o Parque Estadual de Ibitipoca.

No primeiro caso, o governo do Estado de Minas Gerais, graças a um projeto de parceria público-privada (PPP), sob a égide da Lei $\mathrm{n}^{\mathrm{o}}$ 11.079, de 30 de dezembro de 2004, vem promovendo a aproximação entre o governo e o setor privado para garantir a conservação e o desenvolvimento de três UCs estaduais (o Parque Estadual do Sumidouro, o Monumento Estadual Peter Lund e o Monumento Natural Estadual Gruta do Rei do Mato), região localizada ao norte da Região Metropolitana de Belo Horizonte e famosa por sua riqueza científica, cultural e geomorfológica. No caso de uma UC, o interesse público é garantir a conservação, minimizando o aporte de recursos públicos escassos. Em se tratando de parques, há também o interesse em oferecer oportunidades de lazer à população e de engajamento e dinamização do entorno. Assim, quão maior for o potencial de aproveitamento turístico, maior será o interesse do setor privado e, por consequência, menor a demanda por recursos públicos (SEMEIA, 2014).

O caso do Parque Estadual de Ibitipoca é também ilustrativo de como investimentos em infraestrutura básica de visitação, com quantidade pouco expressiva de recursos, podem alavancar os ganhos decorrentes do turismo. A visitação do parque passou por três fases nos últimos anos. Na década de 1990, o aumento do número de visitantes ocorreu de forma pouco organizada, gerando impactos indesejados no ecossistema. O pico de turistas ocorreu em 2002, com 51,8 mil visitantes e esse rápido crescimento causou impactos indesejáveis aos atributos naturais e à biodiversidade local. A adoção de medidas restritivas para proteção ambiental refletiu no fluxo de visitantes, cuja queda não impediu, contudo, que a organização da área e as medidas aplicadas dessem ensejo à prática de um turismo sustentável. Com a 
retomada dos investimentos em 2008, observou-se o aumento da visitação ao parque. Foram incorporadas melhorias relativamente simples ao acesso e à estrutura de recepção do turismo. Atualmente, o parque conta com opções de acampamento, hospedagem e auditórios para locação (SEMEIA, 2014).

É bem verdade que os avanços no incremento do turismo não teriam sido possíveis não fosse o esforço inicial de se adotar modelos de arranjos inovadores. Ou seja, se hoje esses locais conseguem aliar conservação ambiental com desenvolvimento regional, tal se deve à firme crença de que o turismo pode atuar como agente e beneficiário de metas e de políticas públicas voltadas para desenvolvimento.

\section{CONSIDERAÇÕES FINAIS}

De modo geral, instituir uma UC é procedimento simples. Sua manutenção e operação, todavia, são tarefas dispendiosas, quando ocorrem. A despeito do alargamento do escopo da proteção legislativa, do amadurecimento da consciência dos atores envolvidos na preservação ambiental, o desenvolvimento socioeconômico e sustentável nesses espaços protegidos ainda é algo vulnerável. Os parques nacionais, onde a visitação é permitida, representam uma parcela significativa do território brasileiro e ainda carecem de avanços no que tange à uma gestão e planejamento adequados para viabilizar sua existência e seu uso público dentro dos parâmetros ideais e/ou desejados. Nessa seara, acreditamos, com base em exemplos de gerenciamento eficiente em parques internacionais, que o modelo brasileiro pode se inspirar e alavancar a conservação ambiental e o desenvolvimento socioeconômico a passos largos. $\mathrm{O}$ turismo, além de se beneficiar, é um dos instrumentos comprovadamente adequados para o alcance dessa meta.

\section{REFERÊNCIAS BIBLIOGRÁFICAS}

BRASIL. Lei $n^{\circ} 9.985$ de 18 de julho de 2000 e Decreto $n^{\circ} 4.340$ de 22 de agosto de 2002. Regulamenta o art. 225, § $1^{\circ}$, incisos I, II, III e VII da Constituição Federal, institui o Sistema Nacional de Unidades de Conservação da Natureza e dá outras providências. Disponível em: < http://www.planalto.gov.br/ccivil_03/leis/19985.htm >. Acesso em: 21/5/2015.

Lei no 11.079, de 30 de dezembro de 2004. Institui normas gerais para licitação e contratação de parceria público-privada no âmbito da administração pública. Disponível em: < http://www.planalto.gov.br/ccivil_03/_ato2004-2006/2004/lei/111079.htm > . Acesso: 21/5/2015.

BUENO, F. P. e PIRES, P. L. Ecoturismo e educação ambiental: possibilidades e potencialidades de conservação da natureza. IV SeminTUR - Seminário de Pesquisa em Turismo do MERCOSUL Universidade de Caxias do Sul, Caxias do Sul, RS, Brasil - 7 e 8 de julho de 2006. Disponível em: < http://www.ucs.br/ucs/tplSemMenus/eventos/seminarios_semintur/semin_tur_4/arquivos_4_s eminario/GT08-5.pdf > Acesso: 6/5/2105

CARVAlHO, M. C. M. H. O Turismo - Atividade Econômica e Desenvolvimento Sustentável. In: Parcerias Público-Privadas e Turismo: Um modelo de aplicação para 
fomentar o desenvolvimento socioeconômico e o desenvolvimento sustentável no Brasil Estudo de Caso. 1 ed. - Curitiba, PR: Editora CRV, 2014

CAVAlCANTE, M. B. e FURTADO, E. M. Políticas Públicas de Turismo em Unidades de Conservação. Mercator. Fortaleza, v. 10, n. 21, p. 113-146, jan. / abr. 2011.

FARIAS, G. B. e CASTILHO, C. J. M. Observação de aves e ecoturismo em Itamaracá (PE): instrumentos para o desenvolvimento sustentável. Revista Sociedade \& Natureza, vol. 18, núm. 35, diciembre, 2006, pp. 35-53. Universidade Federal de Uberlândia, Uberlândia, Minas Gerais, Brasil.

FONTELES, J. O. Turismo Globalizado. Revista da Casa da Geografia de Sobral, ano 1, n. 1 (1999).

INSTITUTO CHICO MENDES DE CONSERVAÇÃO DA BIOIVERSIDADE. Categorias. Disponível em: < http://www.icmbio.gov.br/portal/biodiversidade/unidades-deconservacao/categorias.html > Acesso: 6/5/2015

INSTITUTO SEMEIA. Disponível em < http://www.semeia.org.br > Acesso: 21/5/2015

Unidades de conservação no Brasil: a contribuição do uso público para o desenvolvimento socioeconômico. São Paulo: Semeia, 2014. 53 p.

MORAES, E. A. Áreas protegidas, inclusão social e turismo. Caderno Virtual de Turismo. Disponível em: < http://www.ivt-rj.net/sapis/2006/pdf/EdilaineMoraes.pdf > Acesso: 04/05/2015

RIVA, A. L. e PETTA, E. Apresentação. In: CARVAlHO, M. C. M. H. Parcerias PúblicoPrivadas e Turismo: Um modelo de aplicação para fomentar o desenvolvimento socioeconômico e o desenvolvimento sustentável no Brasil - Estudo de Caso. 1 ed. Curitiba, PR: Editora CRV, 2014.

SANTOS, C. Globalização, turismo e seus efeitos no meio ambiente. Terra livre, São Paulo, ano 18, v. 2, n. 19, p. 191-198, jul/dez. 2002.

WANDERLEY-FILHA, I.; AZEVEDO, F. F.; NÓBREGA, W. R. M. e ALBUQUERQUE, J. C. Planejamento e Políticas Públicas do Turismo: uma discussão teórica no contexto das Unidades de Conservação do Brasil. Anais do IX Congresso Nacional de Ecoturismo e do V Encontro Interdisciplinar de Turismo em Unidades de Conservação. Revista Brasileira de Ecoturismo, São Paulo, v.6, n.4, nov-2013, pp.27-44. 